\title{
ZUM JAHRESAUSKLANG
}

\section{Liebe Kolleginnen und Kollegen!}

Ein aufregendes Jahr für die OGKA geht zu Ende und ein spannendes neues beginnt. Zeit, also gleichermaßen Rückschau als auch Vorausschau zu halten.

Wir haben 1.508 Teilnehmer an 86 Kursen gehabt. Der große Trend geht wohl hin zum Erwerb von Spezialdiplomen, um seine eigene Spezialisierung auf einem bestimmten Gebiet der Chinesischen Medizin zu unterstreichen, was auch absolut sinnvoll ist. Erfreulicherweise konnten wir dennoch heuer im Herbst den größten $\mathrm{Zu}-$ strom zur Ö̈̈K-Diplomausbildung Körperakupunktur seit vielen Jahren verzeichnen. Das bestätigt unsere Ausrichtung der Ausbildung und den Unterricht unserer Referenten, bei denen ich mich hiermit ganz herzlich für ihr Engagement bedanke!

DerTAO-Kongress im September hat mit dem Hauptthema TCM \& Kinderwunsch 257 Teilnehmer aus 18 Ländern in Graz versammelt und unsere Landeshauptstadt zu einem Mekka für fortbildungswillige TCM-Ärzte gemacht.

Auch die Akupunkturvorlesung an der Medizinischen Universität Graz war mit 150 Teilnehmern ein voller Erfolg und konnte die Studenten absolut für einen integrativen, evidenzbasierten Einsatz der Akupunktur in ihr späteres klinisches Arbeiten begeistern.

So blicken wir auf ein erfolgreiches Jahr für die Akupunktur \& uns als ihre Freunde zurück und freuen uns auf ein genauso intensives und spannendes Jahr der Ratte. Nachdem diesem Tier im chinesischen Horoskop sowohl eine hohe Intelligenz und gute Intuition attestiert werden, Fähigkeiten, mit denen alle Lebenslagen bewältigbar sind, das Jahr 2020 somit im Zeichen des Metalls steht, ein dauerhaftes Material, das Entschlossenheit und Festigkeit symbolisiert, kann es nur ein gutes Jahr werden.
Wer - so wie ich - ein Fan des Disneyfilms „Ratatouille" ist, wird wissen, dass im Jahr der Ratte sicherlich doch einige Überraschungen auf uns warten werden ... wir dürfen also gespannt sein.

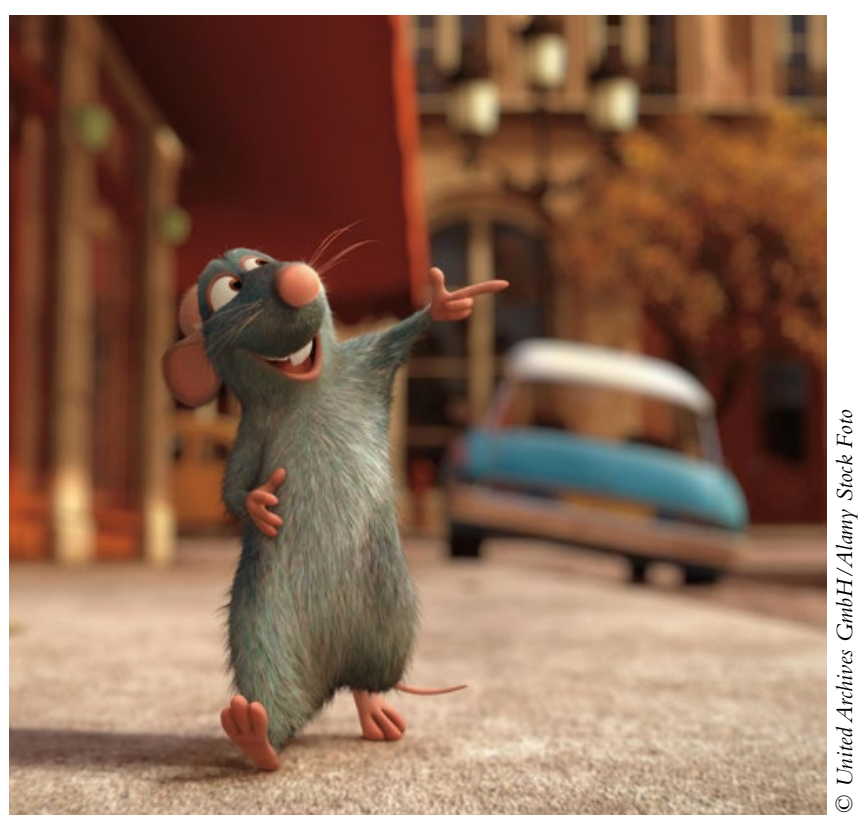

In diesem Sinne wünsche ich Ihnen einen besinnlichen Jahresausklang und ein bombastisches Neues Jahr!

Ihre

Dr. Olivia Krammer-Pojer

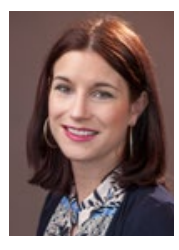

Dr. med. univ. Olivia Krammer-Pojer

Präsidentin der Österreichischen Gesellschaft für kontrollierte Akupunktur und TCM (OGKA)

Glacisstraße 7, A-8010 Graz

Tel. $+43316 / 374050$

E-Mail:office@ogka.at, Internet: www.ogka.at 